\title{
GERENCIAMENTO DA ATIVIDADE INDUSTRIAL COMO FERRAMENTA ESTRATÉGICA PARA FORMAÇÃO DO PREÇO DE VENDA
}

\section{MANAGEMENT OF INDUSTRIAL ACTIVITY AS A STRATEGIC TOOL FOR SELLING PRICE OF TRAINING}

Flávio Alberto Oliva, Lucas Magiolo Crepaldi, Katlin Caroline Patrício Torquato, Amanda Farquetti, Gelson Ricardo de Araújo Oliveira, Graciele Priscila de Oliveira Bravin, Arnaldo Perosso Zulin

Universidade do Oeste Paulista - UNOESTE, Faculdade de Engenharia de Produção, Presidente Prudente, SP.

E-mail: flavio.oliva@unoeste.br

RESUMO - O presente trabalho teve como principal objetivo calcular o preço de venda dos produtos de uma metalúrgica que atua no agronegócio na região de Presidente Prudente - SP. Objetivou-se ainda a integração da atividade produtiva com a gestão empresarial como fator estratégico de competitividade no âmbito do custo de produção e dos possíveis preços de mercado. O modelo em questão permite o entendimento da composição dos custos de cada peça bem como a importância que cada item desempenha no custo total, a formação do preço de venda e o lucro. Os dados foram levantados diretamente na empresa, organizados e tabulados em planilhas eletrônicas.

Palavras-chave: Custos; Preços; Competitividade; Estratégia; Planejamento.

ABSTRACT - This study aimed to calculate the selling price of the products of a metallurgical operating in the agribusiness in the region of Presidente Prudente - SP. The objective was to further the integration of productive activity with corporate management as a competitive strategic factor in the cost of production and possible market prices. The model in question allows the understanding of the composition of each piece costs as well as the importance of each item plays in the total cost, the training of the sales price and profit. The data were collected directly in the company, organized and tabulated in spreadsheets.

Recebido em: 28/07/2015

Keywords: Costs; Prices; Competitiveness; Strategy; Planning. 


\section{INTRODUÇÃO}

A partir da Revolução Industrial, com o surgimento de máquinas e equipamentos, a atividade produtiva foi exigida a produzir com eficiência e eficácia. A atual conjuntura econômica global impõe ritmos competitivos intensos, tanto na qualidade do produto final quanto na sua adequação ao bolso do consumidor. Neste sentido, torna-se imprescindível uma adequada estrutura de gerenciamento industrial, capaz de articular conhecimentos sobre modelos produtivos e condições de mercado, objetivando subsidiar a tomada de decisão e controles que permitam ao negócio a sustentabilidade, a perenidade e a competitividade.

A gestão de custos é uma das principais tecnologias que podem e devem ser adotadas pelas empresas. A principal vantagem oferecida é a capacidade de fornecer informações qualificadas, servindo como suporte na tomada de decisões, além de planejamento e controle dos recursos de produção, estabelecendo uma importante ferramenta gerencial na demanda da sustentabilidade competitiva da empresa. Atualmente a sustentação competitiva se baseia em aspectos que abrangem a conservação, $\mathrm{o}$ crescimento e $\mathrm{O}$ desenvolvimento organizacional (SAKURAI, 1997). Neste trabalho o objetivo buscado foi o cálculo do custo de produção bem como o preço de venda como subsídio para tomada de decisão e controle gerencial.

\section{OBJETIVO}

Definir e aplicar metodologias de custos e formação de preço de venda capaz de subsidiar o gerenciamento, a tomada de decisão e controle da atividade industrial.

\section{MATERIAL E MÉTODOS}

O projeto foi realizado numa metalúrgica que atua no agronegócio produzindo peças para tratores, colhedeiras de cana de açúcar e implementos. Os dados foram levantados na empresa, organizados e tabulados de maneira que a apropriação dos custos de transformação aos produtos elaborados, semielaborados e em elaboração, bem como a apuração do custo total e unitário dos produtos estivessem dispostos numa planilha e, por fim, o cálculo do preço de venda.

\section{RESULTADOS}

Segundo Bruni (2010), a formação dos preços representa uma das mais importantes e nobres atividades empresariais. A definição equivocada do preço pode arruinar um negócio. Embora discussões e dúvidas permaneçam sobre o fato de ser arte ou ciência, existe a certeza de que, sob a óptica da empresa, o preço deve ser superior aos custos plenos incorridos, incluindo os tributos. Da diferença entre os preços e os 
custos plenos e impostos, nasce o conceito de lucro e manutenção das atividades empresariais, porém sob o ponto de vista do consumidor, o preço praticado deve ser inferior ao valor percebido por quem compra o produto ou serviço. A decisão de comprar baseia-se na obtenção de benefícios extras, a diferença existente entre o valor percebido e o preço praticado.

Santos (2008) destaca que a preocupação em formar preços está ligada aos custos, às condições de mercado, às características da concorrência, ao nível de atividade e à remuneração do capital investido ou lucro.

Tabela 1. Matriz de custos e preços de venda

\begin{tabular}{|c|c|c|}
\hline Produto & Custo Total em R\$ & Preço de Venda em R\$ \\
\hline 1 & $1.980,96$ & $3.150,00$ \\
\hline 2 & 2,64 & 4,50 \\
\hline 3 & 7,18 & 11,00 \\
\hline 4 & 34,44 & 55,10 \\
\hline 5 & 5,84 & 10,10 \\
\hline 6 & 15,53 & 24,20 \\
\hline 7 & 313,50 & 415,00 \\
\hline 8 & 33,67 & 70,90 \\
\hline 9 & 94,78 & 136,00 \\
\hline 10 & 26,10 & 41,40 \\
\hline
\end{tabular}

A boa gestão de custos tem seu grande objetivo na maximização dos lucros, cuja eficácia mais contundente é a conquista natural da liderança em custos. É esta a estratégia competitiva principal para levar uma empresa a conquistar mais fatias e permanência assegurada no mercado (POMPERMAYER, 2012). A utilização das técnicas de gerenciamento empresarial permitiu calcular os custos bem como o preço de venda para cada um dos itens produzidos pela metalúrgica. Com resultado, tem-se total controle sobre custos, faturamento e lucro.

\section{DISCUSSÃO}

A competição entre empresas tem aumentado nos mercados internacional e nacional. Esse acirramento da competição dá origem a uma pressão competitiva, que direciona as empresas para a busca de mais eficiência nas suas operações e nos processos de gestão. Trata-se de fenômeno observado de modo marcante nas indústrias.

Historicamente, na atividade industrial, que se percebeu de modo mais 
claro a necessidade de desenvolver com regularidade novos produtos, cada vez mais complexos e com maior grau de diversificação. Em virtude dessa situação geral, que ao longo do tempo passou sistematicamente a impactar os modelos gerenciais vigentes.

As empresas foram compelidas a trabalhar simultaneamente várias dimensões da competição: qualidade, tempo, flexibilidade, inovação e principalmente custo de produção.

É no contexto dessa nova realidade econômica que foram forjados os ditos sistemas de produção modernos. Trata-se de um quadro fundamentalmente distinto daquele que viabilizou a produção em massa fordista e, posteriormente, o crescimento industrial acelerado das décadas de 50 e 60 nos Estados Unidos e na Europa.
Os sistemas de produção modernos compreendem uma ampla variedade de modelos, conceitos e métodos de gestão. Inserem-se nesse conjunto as abordagens do Sistema Toyota de Produção (STP), da produção enxuta (lean manufaturing), do modelo sueco de produção, do controle de qualidade total (TQC), da Teoria das restrições (TOC), da reengenharia de processos de negócios, dos sistemas integrados de gestão (MRPII, ERP, SCM). Na sua origem comum, encontra-se a necessidade das empresas de implantar, de forma contínua e sistemática, sistemas de produção e controle cada vez mais flexíveis e integrados, visando atender às necessidades colocadas pelo mercado no ambiente competitivo contemporâneo (ANTUNES, 2008).

Tabela 2. Custo de Produção

\begin{tabular}{|c|c|c|c|c|}
\hline Produto & Custo Fixo & $\begin{array}{c}\text { Custo Hora } \\
\text { Máquina }\end{array}$ & $\begin{array}{c}\text { Custo Matéria } \\
\text { Prima }\end{array}$ & Custo Total \\
\hline 1 & 142,56 & 394,91 & $1.443,49$ & $1.980,96$ \\
\hline 2 & 0,18 & 1,53 & 0,93 & 2,64 \\
\hline 3 & 0,57 & 4,75 & 1,86 & 7,18 \\
\hline 4 & 2,33 & 10,15 & 11,96 & 34,44 \\
\hline 5 & 0,44 & 4,50 & 0,90 & 5,84 \\
\hline 6 & 1,33 & 6,65 & 7,55 & 15,53 \\
\hline 7 & 19,09 & 17,79 & 276,62 & 313,50 \\
\hline 8 & 3,54 & 3,63 & 26,50 & 33,67 \\
\hline 9 & 7,41 & 40,51 & 46,86 & 94,78 \\
\hline 10 & 2,35 & 11,63 & 12,12 & 26,10 \\
\hline
\end{tabular}


Na determinação do preço de venda de um produto, o gestor estará prevendo na receita de cada unidade a recuperação dos custos e despesas necessários à fabricação e venda da referida unidade, além de uma parcela que possa contribuir para a cobertura de parte dos custos e despesas fixas e com a formação do lucro (MARTINS, 2000).

No entendimento de Crepaldi (2009), refletir sobre a importância de se conhecer e identificar que a formação do preço é um fator determinante para a sobrevivência da exploração da atividade da empresa, a importância de ter os preços compatíveis com o mercado, além de aprender a calcular os custos reais da sua atividade, fazer a gestão estratégica da empresa e trabalhar na identificação de novas oportunidades de mercado e, consequentemente, aumentar a lucratividade.

Dessa maneira, a constituição do preço de venda de um produto será a agregação dos custos, despesas e o lucro desejado. A margem de lucro que será acrescentada ao custo de produção para a obtenção do preço de venda, é conhecida como mark-up, diferença entre o custo total de produção do produto e o seu preço de venda onde, no caso da referida empresa, o mark-up foi calculado mediante análise de preços dos principais concorrentes. Na tabela 3 , estão elencados os produtos, os custos totais de cada produto, os impostos, o mark up em porcentagem e valores, a margem bruta em porcentagem e valores e finalmente o preço de venda. Por meio do referido estudo, tem-se os elementos imprescindíveis para a tomada de decisão e controle das atividades gerenciais da empresa. Para a construção da tabela em questão, foram realizados levantamentos in loco nos setores da empresa como almoxarifado, departamento pessoal, contabilidade e gerência de produção. Os dados levantados subsidiaram a elaboração da tabela 3. Para os propósitos deste estudo, foi utilizado o método de custeio por absorção, adotando como critério hora máquina e hora homem, apontados em cada fase do processo de fabricação de acordo com a ficha técnica. A empresa adota controles de produção norteados pelo critério hora máquina e hora homem, o que justifica a utilização do critério de rateio dos custos indiretos fixos de produção pelo método de absorção.

Com relação ao volume de produção foi considerada a capacidade instalada comparada com a produção efetiva da empresa.

Os produtos fabricados dispõem de ficha técnica e desenho industrial onde são apontados os tempos de processos, mão de obra, consumo de matérias primas e respectivas perdas durante 0 processo produtivo. 
Tabela 3. Custo Total e Preço de Venda

\begin{tabular}{|c|c|c|c|c|c|c|c|c|c|c|c|}
\hline \multirow[t]{2}{*}{ Produto } & \multirow{2}{*}{$\begin{array}{l}\text { Custo } \\
\text { Total }\end{array}$} & \multicolumn{5}{|c|}{ Impostos sobre as Vendas } & \multicolumn{2}{|c|}{ Mark Up } & \multicolumn{2}{|c|}{ Margem Bruta } & \multirow{2}{*}{$\begin{array}{l}\text { Preço } \\
\text { Venda }\end{array}$} \\
\hline & & Pis & Cofins & IRPJ & CSLL & ICM & $\%$ & $\mathrm{R} \$$ & $\%$ & $\mathrm{R} \$$ & \\
\hline 1 & $1.980,96$ & 2,3 & 10,8 & 1,2 & 1,08 & 4,1 & 71,3 & 1311,60 & 28,0 & 555,42 & $3.150,00$ \\
\hline 2 & 2,64 & 2,3 & 10,8 & 1,2 & 1,08 & 4,1 & 82,9 & 2,04 & 37,4 & 0,99 & 4,50 \\
\hline 3 & 7,18 & 2,3 & 10,8 & 1,2 & 1,08 & 4,1 & 66,4 & 4,39 & 19,0 & 1,36 & 11,00 \\
\hline 4 & 34,44 & 2,3 & 10,8 & 1,2 & 1,08 & 4,1 & 71,6 & 22,99 & 28,8 & 9,92 & 55,10 \\
\hline 5 & 5,84 & 2,3 & 10,8 & 1,2 & 1,08 & 4,1 & 87,0 & 41,70 & 39,2 & 2,29 & 10,10 \\
\hline 6 & 15,53 & 2,3 & 10,8 & 1,2 & 1,08 & 4,1 & 70,4 & 10,00 & 25,5 & 3,96 & 24,20 \\
\hline 7 & 313,50 & 2,3 & 10,8 & 1,2 & 1,08 & 4,1 & 41,0 & 120,59 & 6,6 & 20,66 & 415,00 \\
\hline 8 & 33,67 & 2,3 & 10,8 & 1,2 & 1,08 & 4,1 & 153,3 & 40,77 & 69,6 & 23,42 & 70,90 \\
\hline 9 & 94,78 & 2,3 & 10,8 & 1,2 & 1,08 & 4,1 & 55,7 & 48,63 & 15,5 & 14,73 & 136,00 \\
\hline 10 & 26,10 & 2,3 & 10,8 & 1,2 & 1,08 & 4,1 & 74,3 & 12,65 & 27,7 & 7,23 & 41,40 \\
\hline
\end{tabular}

\section{CONCLUSÃO}

A aplicação de um modelo de análise gerencial sobre o comportamento dos custos de produção poderá trazer subsídios para controles e tomadas de decisões mais acertadas. Permitirá a elaboração do preço de venda bem como conhecer a margem de contribuição e a margem de lucro de cada produto produzido. Torna-se, neste sentido, ferramenta indispensável para o atual ambiente de competitividade global.

\section{REFERÊNCIAS}

ANTUNES, J. A. V. Sistemas de produção: conceitos e práticas para projetos de gestão da produção. 1. ed. Porto Alegre: Bookman, 2008.

BRUNI, A. L. Administração de custos, preços e lucros. 4. ed. São Paulo: Atlas, 2010.
CREPALDI, S. A. Curso básico de contabilidade de custos. 4. ed. São Paulo: Atlas, 2009.

MARTINS, E. Contabilidade de custos. 7. ed. São Paulo: Atlas, 2000.

POMPERMAYER, C. Gestão de Custos. 2012. http://pt.slideshare.net/CristianDeOliveiraAb reu/artigo. Acesso em: 28 maio 2015.

SAKURAI, M. Gerenciamento integrado de custos. São Paulo: Atlas, 1997.

SANTOS, M. L. Processos de formação de preços. Curitiba: lesde, 2008. 